\title{
Modeling determinants of growth: evidence for a community-based target in height?
}

\author{
Christian Aßmann ${ }^{1}$ and Michael Hermanussen ${ }^{2}$
}

BACKGROUND: Human growth is traditionally envisaged as a target-seeking process regulated by genes, nutrition, health, and the state of an individual's social and economic environment; it is believed that under optimal physical conditions, an individual will achieve his or her full genetic potential.

METHODS: Using a panel data set on individual height increments, we suggest a statistical modeling approach that characterizes growth as first-order trend stationary and allows for controlling individual growth tempo via observable measures of individual maturity. A Bayesian framework and corresponding Markov-chain Monte Carlo techniques allowing for a conceptually stringent treatment of missing values are adapted for parameter estimation.

RESULTS: The model provides evidence for the adjustment of the individual growth rate toward average height of the population.

CONCLUSION: The increase in adult body height during the past 150 y has been explained by the steady improvement of living conditions that are now being considered to have reached an optimum in Western societies. The current investigation questions the notion that the traditional concept in the understanding of this target-seeking process is sufficient. We consider an additional regulator that possibly points at community-based target seeking in growth.

n the 1960s, Tanner (1) inaugurated the idea of growth as a target-seeking process regulated by genes, nutrition, health, and the state of an individual's social and economic environment: optimal conditions are expected to result in the achievement of a person's full genetic potential. The idea fathered considerable efforts in social, economic, and demographic history and produced evidence for interactions among living conditions, technology, economy, and average body height $(2,3)$. Although the steady improvement of living conditions provided good arguments for the increase of height in recent European history, it failed to explain why adolescent height converges toward the average of the population. Height tends to cluster. The within-population variation of height is narrow. This is particularly evident when analyzing height distributions at different moments in history.

In the nineteenth century, people were short. Analyzing data sets on conscripts providing a complete representation of a population under consideration, including those considered fit for military service and those who are not drafted, reveals that in 1863, the average Dutch conscript reached $165 \mathrm{~cm} \mathrm{(4),} \mathrm{and}$ $<1 \%$ of these conscripts reached $184 \mathrm{~cm}$, the mean body height of modern Dutch men (5). Thirty percent of the historic conscripts failed to reach $157 \mathrm{~cm}$. This is peculiar. Common sense might expect at least a few affluent, well-fed, healthy 19thcentury adolescents to achieve modern height; and vice versa, we might expect at least a few malnourished, chronically-ill, and underprivileged modern subjects to remain below the mid-nineteenth century's 30\% quantile. But this is not the case. Height distributions of European conscripts tended to shift in toto, with surprisingly little overlap between historic and modern height. Figure 1 exemplifies five cohorts, all from Switzerland (6). Although these cohorts share the same genetic pool, they are physically segregated by up to $130 \mathrm{y}$. In the late nineteenth century, height clustered around $163.3 \mathrm{~cm}$; modern height clusters around $178.2 \mathrm{~cm}$. No historic conscript reached the modern 90 th percentile of height, and $<3 \%$ of the modern conscripts are shorter than the nineteenth-century average.

The forces that drive secular trends in height do not appear to be equally distributed throughout childhood and adolescence. Much of the secular height gain since the end of the nineteenth century is due to an enhancement of adolescent height gain. We will give a representative example.

In 1893, Camerer (7) performed a growth study in German children and adolescents from birth to $18 \mathrm{y}$. In those days, children appeared shorter than today, but they developed at slower pace. The adolescent growth spurt was retarded by almost $2 \mathrm{y}$ as compared with modern growth as exemplified by the modern study published in 2011 (8). The apparent shortness of the young age cohorts was largely due to the delay in developmental tempo, leading to increasing differences in height between the historic and the modern study, from $1.6 \mathrm{~cm}$ at the age of $1.0 \mathrm{y}$ to $3.2 \mathrm{~cm}$ at the age of $2 \mathrm{y}$, to $5.6 \mathrm{~cm}$ at the age of $4 \mathrm{y}$, and to a maximum of $16.3 \mathrm{~cm}$ at the age of $14.5 \mathrm{y}$. Figure 2 illustrates body height of boys measured in 1893 (solid line) and 2011 (dashed line). Age is given as calendar age. Height differences increase with calendar age. Mapping peak height velocity of the two cohorts and thus superimposing the same developmental tempo shows that "tempo-adjusted" height differs 


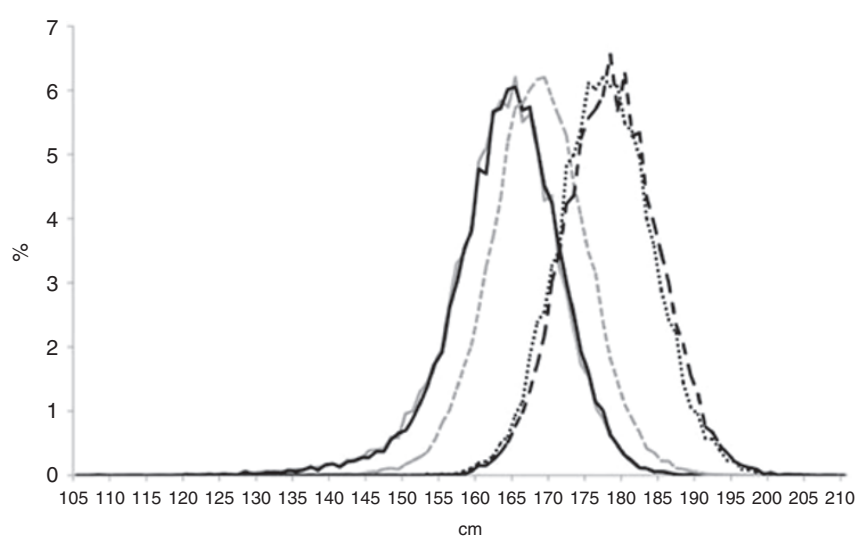

Figure 1. Height distribution of five cohorts of 19-year-old Swiss conscripts from $1878 / 1879$ to $2008 / 2009$ (representing $~ 90 \%$ of the total census population). Solid gray line: conscripts born in 1859-1860 and conscripted in 1878-1879, with a mean height of $163.3 \mathrm{~cm}$. Solid black line: conscripts born in 1872 and conscripted in 1891, with a mean height of $163.7 \mathrm{~cm}$. Broken gray line: conscripts born in 1908-1913 and conscripted in 1927-1932, with a mean height of $168.6 \mathrm{~cm}$. Dashed black line: conscripts born in 1974-1975 and conscripted in 1993-1994, with a mean height of $177.4 \mathrm{~cm}$. Broken black line: conscripts born in 1989-1990 and conscripted in 2008-2009, with a mean height of $178.2 \mathrm{~cm}$. This figure is reprinted from ref. 6 with permission from EMH Schweizerischer Ärzteverlag AG (http://www.smw.ch).

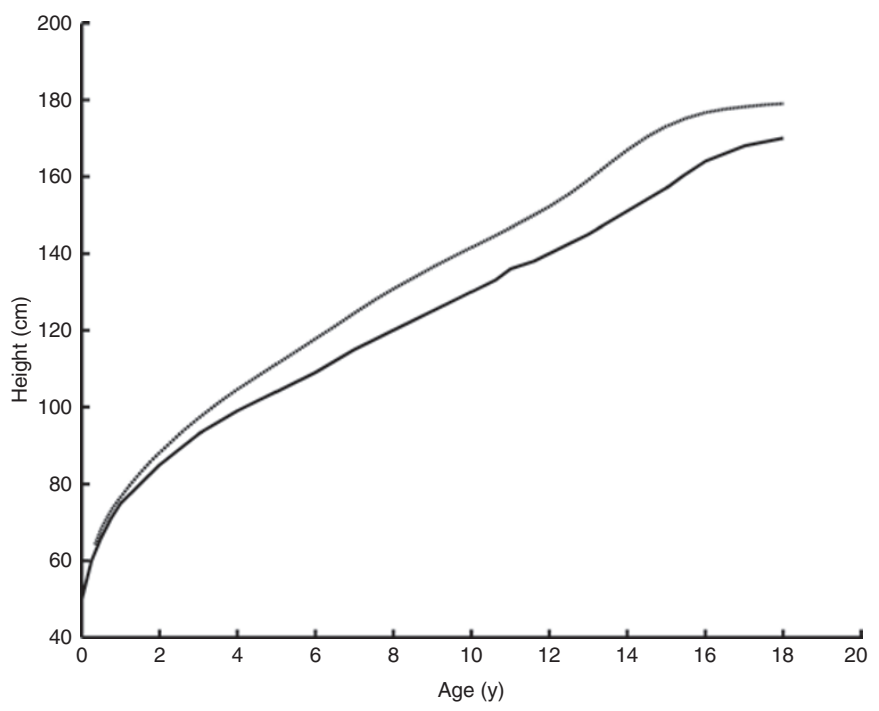

Figure 2. Body height of boys measured in 1893 (solid line) and 2011 (dashed line). Age is given as calendar age. Height differences increase with age.

to a lesser extent. Figure 3 illustrates age as biological age (tempo-adjusted age). Height differences are small throughout childhood but markedly increase during adolescence. In fact, "tempo-adjusted" children in 1893 were almost as tall as modern children. The differences in final height are due to differences in adolescent height gain. Adolescent growth was blunted in the 1893 sample.

Who sets the target for final height? Which mechanisms direct height? Why was adolescent height gain in the late 19th century so mingy? Was it nutrition? Was it health? Was it the socioeconomic situation? Why were the wealthy Europeans

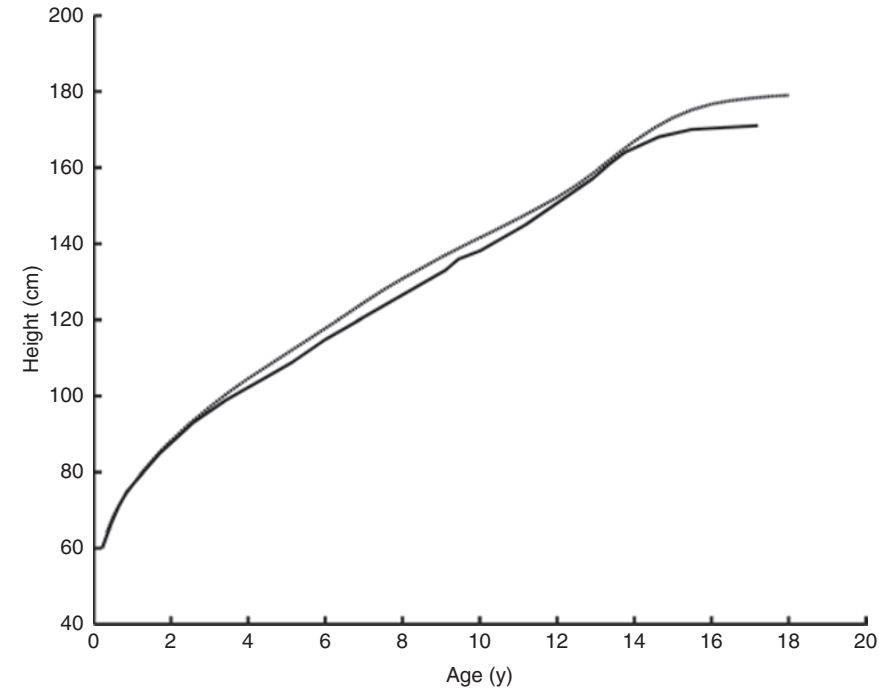

Figure 3. Body height of boys measured in 1893 (solid line) and 2011 (dashed line). Age is given as biological age with tempo adjustment via mapping peak height velocity of both cohorts. Height differences are initially small and markedly increase during adolescence.

of the mid-nineteenth century shorter than any poor modern descendent? Why is the migrant child short but catches up in the new surroundings? These questions matter. Physical growth and attained body height belong to the most delicate biological parameters for estimating health and economic prosperity in developing countries; they are of major importance for everyday pediatric decisions.

Finally, we ask the most exciting questions: what mechanism counteracts height scattering in young adults and keeps individual height so close to average height? Why were the wealthy subjects in the late nineteenth century closer to the late nineteenthcentury average height and even shorter than the underprivileged subjects of today? While having no final answers to these questions, we started to question the traditional role of nutrition, health, and a comfortable social and economic environment for the achievement of a person's full genetic growth potential.

This article suggests a statistical modeling approach incorporating manifold determinants of human growth. The suggested model framework addresses three analytical problems in auxology. First, it allows for testing the hypothesis about ecological determinants of growth variation; second, the developed estimation methodology accounts for missing values via data augmentation; and third, it models serial correlation in growth measurements. Individual growth increments are thereby characterized as time and individual specific. Moreover, individual characteristics of maturity in terms of reached Tanner stages, as well as individual bone age as a proxy of developmental tempo, are incorporated as growth determinants. In addition, individual annual height increments are considered to depend on past height increments in order to capture measurement errors or recapture effects due to individual developmental tempo. Beyond all these variables, the statistical characterization is enriched by an additional factor influencing individual growth, i.e., past deviation from mean 
height. This further factor seems to be essential for the correct characterization of the statistical properties of the growth process. We expect that the smaller the adolescent is compared with past mean average height, the more the adolescent grows during puberty. However, a substantive interpretation is only possible conditional on the assumed time trending behavior of body height. We suggest interpreting the statistical characterization as a backward-looking mechanism, in which an individual's growth depends on his/her past relative height position. We are aware of the fact that this interpretation is a nontestable implication of our statistical modeling approach.

\section{RESULTS}

In the following sections, we discuss the results of the preferred model specification (see Methods) according to the conducted robustness checks. Comparative analysis of alternative time trending specifications based on the marginal likelihood suggests characterizing height increments statistically best as first-order trend stationary (see Supplementary Appendix S1 online for details). Parameter estimates and corresponding highest-density intervals are given in Tables 1 and 2 for boys and girls, respectively. The model parameters $\left\{\sigma_{t}\right\}_{t=9}^{T}$ denote the time-specific conditional variation in height increments. Conditional variation is largest in 15- and 16-y-old boys and in 14 -y-old girls. The model parameters $\left\{a_{t}\right\}_{t=9}^{T}$ show the patterns of age-specific average growth with maxima in mid-puberty. The model parameter set $\left\{b_{t}\right\}_{t=9}^{T}$ indicates that an association exists between subsequent annual height increments. The model parameters $\left\{\gamma_{t}\right\}_{t=9}^{T}$ indicate the association between tempo of maturation assessed in terms of bone age and growth. Those who mature at accelerated tempo grow faster and appear to be tall among their age-mates before puberty, but thereafter, they grow less and reach final height earlier. Those who mature at delayed tempo grow at a slower rate and temporarily appear to be short among their age-mates. In line with common practice, we captured the tempo of maturation by bone age and by the state of pubertal maturation (9). Table 2 lists data about the corresponding parameter estimates capturing the influence of reached Tanner stages on individual height.

To assess the importance of the considered additional factor, which we suggest labeling as "backward-looking mechanism," we compared three different specifications differing with respect to the set of variables controlling for tempo. The first specification includes all tempo control variables and the suggested additional variables $s_{\mathrm{it}}, t=9, \ldots, T$ aiming at capturing the dynamic stochastic properties of height increments. The second specification drops the variables $s_{\mathrm{it}} t=9, \ldots, T$, whereas the third specification checks the evidence of the model, when bone ages $z_{\mathrm{it}}, t=9, \ldots, T$ are omitted as an explaining factor for individual tempo differences. By comparing these three different model specifications, insight is gained into the ability of the different variables to contribute to the explanation of individual height increments. The corresponding marginal likelihoods indicate that the model specification comprising both the bone age and the "backward-looking mechanism" is preferred strongly against the two alternative specifications, for both boys and girls. Furthermore, by comparison with the specification incorporating only bone age, it is evident that the "backward-looking mechanism" provides clearly additional explanatory power (Table 3). Given our measures against the possibility of spurious significance of the "backward-looking mechanism," i.e., the statistical artifact of regression to the mean, this at least allows us to conclude that this additional factor indeed controls not only for individual tempo differences but also is an essential part of the statistical characterization of height increments. Alternatively, one could argue that the parameter set $\left\{\kappa_{t}\right\}_{t=9}^{T}$ is at least an alternative tempo control measure enhancing the performance of the empirical growth model. Detailed results for the set of parameters $\left\{\kappa_{t}\right\}_{t=9}^{T}$ for boys and girls are provided in Table 2, lower part.

In early puberty, the parameter $\kappa_{t}$ governing the influence of past relative height, $s_{i t}$ is positive and adds to the height variation within a population. Those who are tall become taller, and those who are short, will further drop back in height. Thereafter, however, the influence becomes negative, which thus confirms our expectations. The parameter set $\left\{\kappa_{t}\right\}_{t=9}^{T}$ captures the relationship between an individual's height increment and the difference between his/her height and average height of the community in the last period. We suggest thinking of this as an mechanism in which adolescents perceive height in relation to height of their peers.

\section{DISCUSSION}

Malnourished children are short, ill children are short, and children from low socioeconomic background tend to be short. Improvements in nutrition, public health, and the social and economic environment, i.e., improving living conditions, have abundantly been demonstrated to result in the improvement of child and adolescent growth and final height $(2,3)$. Yet the nutritional effect on growth appears to be restricted to developmental tempo (10). Even longstanding starvation has little or no effect on final height, as exemplified by war cohorts of Oslo schoolchildren. They starved for several years and were short during adolescence but completely caught up with those cohorts who matured before the political catastrophe and reached an adequate final height (11). Similar observations were reported from German children and adolescents during and after World War II (12). Moreover, chronic illnesses often appear to exert little effects on final height. Short stature in cystic fibrosis results from tempo deceleration (13). Cystic fibrosis patients grow poorly at all ages (they have suboptimal peak height velocity and late pubertal growth, influenced by disease severity) but eventually achieve normal final height. Wiedemann et al. (14) stated that in a group of 4,306 cystic fibrosis patients, the initially low height $z$-scores increased with age, and normal means for height were reached in the adult age group. Children from low socioeconomic background tend to be short. Moreover, the few affluent, well-fed, healthy sons and daughters of the wealthy nineteenth-century merchants, senators, and other burghers remained short. Figure 1 illustrates two historic Swiss conscript cohorts that cluster around the average. Clustering of height is also obvious in migrants. Maya 


\section{Conditional modeling of human growth $\mid$ Articles}

Table 1. Parameter estimates for $\left\{\sigma_{t}^{2}, a_{t}, b_{t}, \gamma_{t}\right\}_{t=9}^{18}$

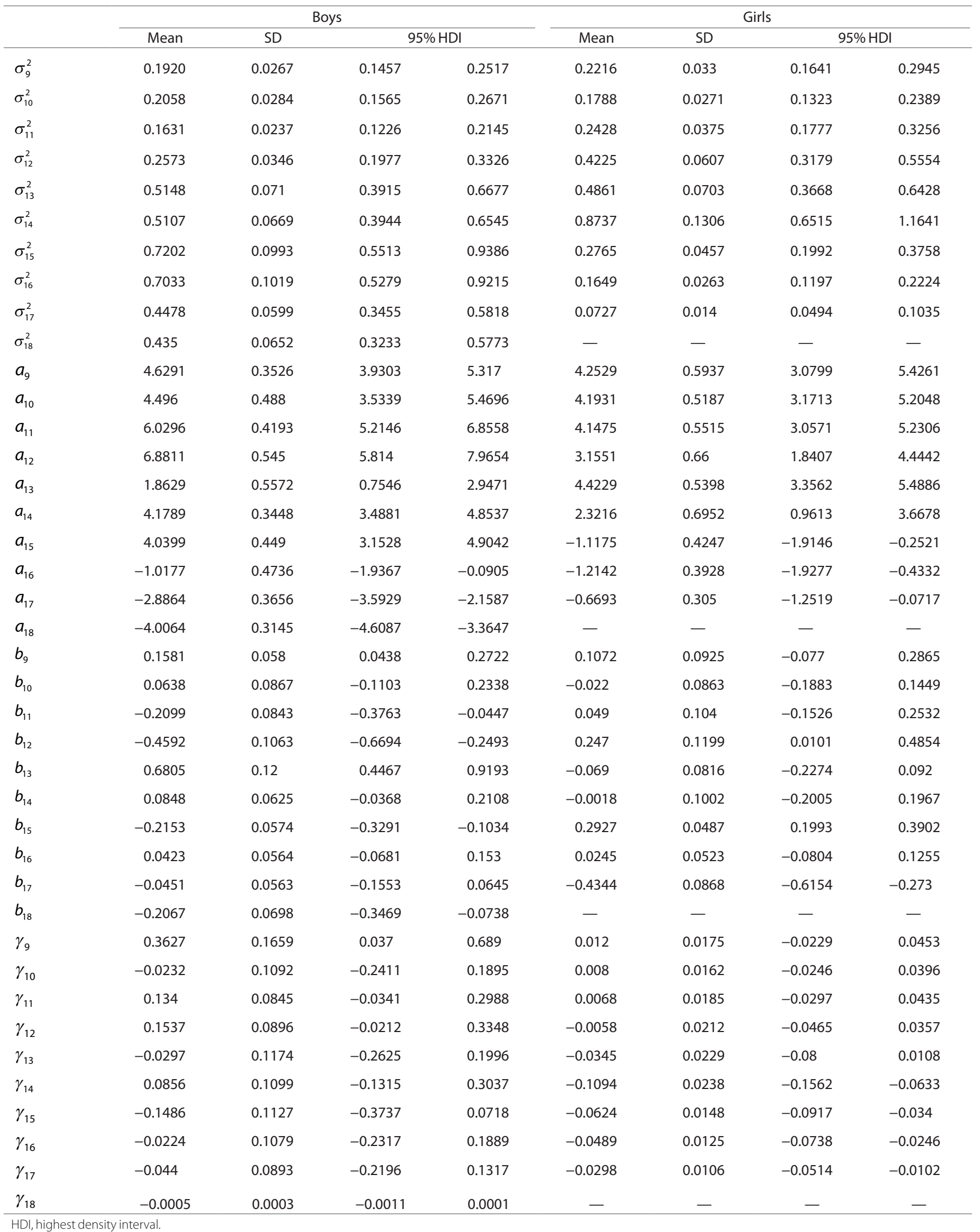


Table 2. Parameter estimates $\sigma_{c}^{2},\left\{\lambda_{t}^{(k)}\right\}_{t=9}^{18}, k=1, \ldots, K,\left\{\kappa_{t}\right\}_{t=9}^{18}$

\begin{tabular}{|c|c|c|c|c|c|c|c|c|}
\hline \multirow[b]{3}{*}{$\sigma_{c}^{2}$} & \multicolumn{4}{|c|}{ Boys } & \multicolumn{4}{|c|}{ Girls } \\
\hline & \multirow{2}{*}{$\begin{array}{c}\text { Mean } \\
0.0414\end{array}$} & \multirow{2}{*}{$\begin{array}{c}\text { SD } \\
0.0081\end{array}$} & \multicolumn{2}{|c|}{$95 \% \mathrm{HDI}$} & \multirow{2}{*}{$\begin{array}{l}\text { Mean } \\
0.0612\end{array}$} & \multirow{2}{*}{$\begin{array}{c}\text { SD } \\
0.0151\end{array}$} & \multicolumn{2}{|c|}{$95 \% \mathrm{HDI}$} \\
\hline & & & 0.0284 & 0.0602 & & & 0.0380 & 0.0979 \\
\hline Menarche & - & - & - & - & 0.6470 & 0.2087 & 0.2487 & 1.0626 \\
\hline Testes/breast maturity - (2) & -0.1984 & 0.0993 & -0.3894 & -0.0028 & 0.0355 & 0.1014 & -0.1603 & 0.2343 \\
\hline Testes/breast maturity - (3) & 0.3416 & 0.1252 & 0.0990 & 0.5863 & 0.4661 & 0.1468 & 0.1782 & 0.7592 \\
\hline Testes/breast maturity - (4) & 1.2312 & 0.1946 & 0.8535 & 1.6105 & 0.0947 & 0.1945 & -0.2890 & 0.4776 \\
\hline Testes/breast maturity - (5) & -0.2064 & 0.1770 & -0.5492 & 0.1451 & -0.7114 & 0.1396 & -0.9841 & -0.4350 \\
\hline Pubic hair - (2) & 0.0429 & 0.1068 & -0.1636 & 0.2570 & 0.2479 & 0.1059 & 0.0394 & 0.4570 \\
\hline Pubic hair - (3) & 0.5583 & 0.1529 & 0.2620 & 0.8534 & 0.2616 & 0.1395 & -0.0033 & 0.5380 \\
\hline Pubic hair - (4) & 0.9095 & 0.1961 & 0.5249 & 1.2963 & 0.1580 & 0.1718 & -0.1821 & 0.4944 \\
\hline Pubic hair - (5) & 0.0890 & 0.2018 & -0.3066 & 0.4882 & -0.3999 & 0.1411 & -0.6691 & -0.1216 \\
\hline Timing of menarche & - & - & - & - & 2.0238 & 0.4888 & 1.0985 & 2.9950 \\
\hline Timing of testes/breast maturity - (2) & 0.1196 & 0.0534 & 0.0152 & 0.2226 & 0.1325 & 0.0453 & 0.0435 & 0.2210 \\
\hline Timing of testes/breast maturity - (3) & -0.1094 & 0.0699 & -0.2460 & 0.0285 & -0.1325 & 0.0779 & -0.2832 & 0.0232 \\
\hline Timing of testes/breast maturity - (4) & -0.3122 & 0.1229 & -0.5530 & -0.0730 & -0.4469 & 0.0835 & -0.6118 & -0.2818 \\
\hline Timing of testes/breast maturity - (5) & 0.1109 & 0.0908 & -0.0643 & 0.2886 & -0.1042 & 0.0485 & -0.1991 & -0.0110 \\
\hline Timing of pubic hair - (2) & -0.0126 & 0.0492 & -0.0837 & 0.1091 & -0.1431 & 0.0437 & -0.2322 & -0.0585 \\
\hline Timing of pubic hair - (3) & -0.1941 & 0.0671 & -0.3243 & -0.0650 & -0.0844 & 0.0772 & -0.2339 & 0.0662 \\
\hline Timing of pubic hair - (4) & 0.0262 & 0.1150 & -0.1992 & 0.2513 & -0.1675 & 0.0952 & -0.3513 & 0.0198 \\
\hline Timing of pubic hair - (5) & -0.3917 & 0.1137 & -0.6108 & -0.1658 & 0.0655 & 0.0556 & -0.0423 & 0.1756 \\
\hline Peak height velocity & 2.6357 & 0.2136 & 2.2101 & 3.0473 & 1.5285 & 0.1726 & 1.1820 & 1.8627 \\
\hline Timing of peak height velocity & -0.7647 & 0.1114 & -0.9847 & -0.5482 & -0.2209 & 0.0691 & -0.3578 & -0.0873 \\
\hline$\kappa_{9}$ & 0.0086 & 0.0138 & -0.0184 & 0.0356 & 0.0120 & 0.0175 & -0.0294 & 0.0453 \\
\hline$\kappa_{10}$ & 0.0464 & 0.0126 & 0.0213 & 0.0712 & 0.0080 & 0.0162 & -0.0309 & 0.0396 \\
\hline$\kappa_{11}$ & 0.0587 & 0.0123 & 0.0347 & 0.0826 & 0.0068 & 0.0185 & -0.0360 & 0.0435 \\
\hline$\kappa_{12}$ & 0.0425 & 0.0142 & 0.0145 & 0.0707 & -0.0058 & 0.0212 & -0.0549 & 0.0357 \\
\hline$\kappa_{13}$ & 0.0033 & 0.0180 & -0.0325 & 0.0385 & -0.0345 & 0.0229 & -0.0881 & 0.0108 \\
\hline$\kappa_{14}$ & -0.0641 & 0.0173 & -0.0982 & -0.0307 & -0.1094 & 0.0238 & -0.1660 & -0.0633 \\
\hline$\kappa_{15}$ & -0.0747 & 0.0174 & -0.1090 & -0.0406 & -0.0624 & 0.0148 & -0.0981 & -0.0340 \\
\hline$\kappa_{16}$ & -0.0919 & 0.0176 & -0.1266 & -0.0575 & -0.0489 & 0.0125 & -0.0789 & -0.0246 \\
\hline$\kappa_{17}$ & -0.0227 & 0.0153 & -0.0529 & 0.0075 & -0.0298 & 0.0106 & -0.0556 & -0.0102 \\
\hline$\kappa_{18}$ & -0.0086 & 0.0135 & -0.0349 & 0.0178 & - & - & - & - \\
\hline
\end{tabular}

HDI, highest density interval.

American children born in families from Guatemala who migrated to the United States are $11.54 \mathrm{~cm}$ taller than Maya children living in Guatemala. Migrant height distribution shifts in toto (15) and clusters near the new US target.

Taken together, these findings have prompted us to search for other mechanisms that might regulate growth in the adolescent and lead to the narrowing in height variation mentioned. We incorporate an additional "backward-looking mechanism" in growth conceptualized as an interaction between the difference between past average height of a group and individual height and individual height increments. We suggest that this mechanism may capture the observed height scattering within an individual's social habitat and would like to point to the possibility of a "community-based target" in height. We are well aware that our modeling may just have pointed out a further necessary and easily available control for individual tempo when modeling height increments. However, the documented additional factor may also possibly modulate long-term patterns of growth. Measurements in schoolchildren $(11,12)$ and in conscripts indicate that adolescent cohorts, regardless of whether they grew up under fortunate circumstances or during war, illness, and starvation, aim for that height that smoothly fits into the population. The starved, unhealthy, and socially disadvantaged cohorts do not differ from those who grew up under fortunate circumstances. The idea that tall communities generate tall people even in the presence of unfortunate living 
Table 3. Model comparison

\begin{tabular}{|c|c|c|c|c|}
\hline & \multicolumn{2}{|c|}{ Boys } & \multicolumn{2}{|c|}{ Girls } \\
\hline & $\mathrm{LL}$ & $\mathrm{ML}$ & $\mathrm{LL}$ & $M L$ \\
\hline Complete & -955.4 & -755.2 & -653.7 & -785.1 \\
\hline No $\left\{S_{i t}\right\}_{t=9}^{T}$ & -984.6 & -783.6 & -666.9 & -794.1 \\
\hline No $\left\{Z_{i t}\right\}_{t=9}^{T}$ & -974.8 & $-1,119.0$ & -665.7 & -815.6 \\
\hline \multicolumn{5}{|c|}{$\begin{array}{l}\text { LL and ML denote the log likelihood and the log marginal likelihood. Differences } \\
\text { between log marginal likelihoods yield Bayes factors }(B) \text {, which can be gauged based } \\
\text { on Jeffreys'scale. If } B<0, \text { no evidence for the specification under the null hypothesis } \\
\text { is present, whereas for } 0 \leq B \leq 1.15 \text {, very slight evidence is present in favor of the null } \\
\text { hypothesis; with } 1.15 \leq B \leq 2.3 \text {, the evidence is slight; strong evidence is present for } \\
2.3 \leq B \leq 4.6 \text { and very strong evidence is found for } B \geq 4.6 \text {. }\end{array}$} \\
\hline
\end{tabular}

conditions has major impact with respect to the interpretation of child and adolescent height for public health issues and the making of medical decisions. Being short may not necessarily be an indicator of poor nutrition, poor health, or poor socioeconomic background; it may simply indicate that the group to be identified with is short. Establishing this sort of mechanism solidly would require details that are probably not available in any study performed to date. Although communitylevel effects could be explained, e.g., by intragroup dynamics related to nutrition and activity levels, the corresponding necessary methodological challenges are beyond the scope of this article. We are aware of the fact that we are unable to provide satisfying explanations or biochemical pathways that might drive this mechanism. We may speculate that growth hormone $(\mathrm{GH})$ and insulin-like growth factor-1 (IGF-1) are involved. GH determines growth predominantly via IGF-1. $\mathrm{GH}$ is related with emotions. Nonorganic failure to thrive has long been associated with neuroendocrine disturbances (16). It is known that GH is deregulated in childhood depression (17). In the case of exogenous administration, GH increases height even in children without GH deficiency (e.g., ref. 18), with IGF-1 being a potent mediator of this effect. GH and in sequela IGF-1 are potent growth promoters. At present, one might consider these endocrine factors the most promising candidates in this scenario. Yet at present, only few studies deal with the association between social rank and IGF-1. Kumari et al. (19) examined the association of IGF-1 with social position measured by father's or own occupational class in a cohort of individuals born in 1 mo in $1958(n=3,374$ men and 3,302 women). They found lower IGF-1 levels in participants with lower social position. Sapolsky and Spencer (20) related social rank and IGF-1 concentrations in male baboons. Social subordinance was associated with a relative suppression of IGF-1 concentrations. They suggested that the individual differences in IGF-1 profiles were a consequence, rather than a cause, of the rank difference. The magnitude of difference in IGF-1 levels among baboons of differing ranks was considered to be of physiological significance.

\section{Conclusion}

This investigation provides strong evidence for a statistical representation adding past relative height to existing controls of individual developmental tempo such as bone age and Tanner stages. The analysis provides strong statistical evidence for this factor. As one possible interpretation, we suggest interpreting this additional factor as a target-seeking mechanism for growth, in which final height is set by the community.

\section{METHODS}

Our statistical modeling approach is based on two basic observations: first, observed height results from annual height increments, which are characterized as individual and time specific. Second, individual height increments should be modeled conditional on observable maturity indicators, allowing for control of individual growth tempo. We analyzed longitudinal height data, based on measurements of height, weight, pubertal stage, and bone age, from 69 boys, 9-18 y, and 60 girls, 9-17 y (21) of the First Zurich Longitudinal Growth Study. The boys and girls were all of Swiss origin, and their parents lived in the city of Zurich or in its immediate vicinity, i.e., this sample was not obtained as a representative sample from a large population but originated from a single community. We suggest the following modeling framework, i.e.,

$$
g_{i t}=a_{t}+b_{t} g_{i t}+c_{i}+\gamma_{t} z_{i t}+\sum_{k=1}^{K} \lambda_{i t}^{(k)}+\kappa_{t} s_{i t}+e_{i t},
$$

where $c_{i} \sim N\left(0, \sigma_{t}^{2}\right), e_{i t} \sim N\left(0, \sigma_{t}^{2}\right)$, and let $g_{i t}=h_{i t}-h_{i t-1}, c_{i}$ independent of $e_{i t}$, and $t=9, \ldots, T, i=1, \ldots, N$. Further details on estimation are provided in Supplementary Appendix S1 online. The meaning of each included model component is given in the following:

1. Age is a factor that determines the annual increment in height: in early childhood, annual height increments are larger than in late childhood, and there is a second peak in height gain during adolescence. The model captures this characteristic growth pattern via the parameter set $\left\{a_{t}\right\}_{t=9}^{T}$

2. Height increments of subsequent years may be related to each other: periods of accelerated growth may alternate with periods of slower growth, several growth spurts have been described during early and late childhood (22), or periods of temporary growth arrests due to illness and starvation may be compensated by so-called "catch-up" growth (23), and measurement errors may lead to a negative association of subsequent growth rates. We incorporated a term modeling autoregressive or "compensatory growth" captured by the parameter set $\left\{b_{t}\right\}_{t=9}^{T}$.

3. A child-specific term allows for all-time characteristics of a child such as familial tall or short stature captured by the parameter set $\left\{c_{i}\right\}_{i=1}^{N}$, conceptualized as a random effect with variance $\sigma_{c}^{2}$.

Tempo of maturation is a factor that determines the annual increment in height. The fast-maturing child may temporarily appear tall, will reach puberty early, but may lose his growth advantage in adulthood (24).We expect thus a bimodal influence of the state of maturity: larger annual height increments before mid-adolescence in the fast-maturing individuals and smaller annual height increments thereafter; and we expect smaller annual height increments before mid-adolescence in the slow-maturing individuals and larger annual height increments thereafter. Our model accounts for the state of maturity, as it includes:

4. Skeletal maturation, conventionally named "bone age," captured by the parameter set $\left\{\gamma_{t}\right\}_{t=9}^{T}$ and

5. Tanner stages of puberty, captured by the parameter set $\left\{\lambda_{t}^{(k)}\right\}_{t=9}^{T}$, $k=1, \ldots, K$.

Note that the considered indicators of maturity comprise pubic hair maturity (boys and girls), breast maturity (girls), maturity of testes (boys), peak of height velocity (boys and girls), and time of menarche (girls). Each factor is measured using the Tanner stages, except for peak of height velocity and time of menarche. Each factor influences factors in two ways. The factors enter directly the growth 
process as well in relation to mean time of the factors (and related Tanner stages) (for details, see Supplementary Appendix S1 online).

The considered growth model thus includes well-known contributors to growth and height variation, including the two factors of maturity that pay reference to the variation in tempo. We suggest incorporating a further factor in order to provide a valid statistical characterization of annual height increments. As we create a timeand individual-specific factor that captures the scattering of individual height around the community average and assess the association between individual height and growth, and average height within the group, i.e., $s_{i t}=h_{i t-1}-\frac{1}{N} \sum_{i=1}^{N} h_{i t-1}$, we characterize individual height increments as first-order trend stationary. The corresponding effects on individual growth are captured by the parameter set $\left\{\kappa_{t}\right\}_{t=9}^{T}$. We expect negative signs within this parameter set, implying that those who are above average in $t-1$ decelerate and those below average accelerate.

The parameters of the above-described model are estimated within a Bayesian approach using Markov-chain Monte Carlo methodology. A Bayesian approach allows a flexible handling of the missing values occurring within this data set and incorporates parameter uncertainty within the parameter estimates (see ref. 25 for a general review of the principles for Bayesian analysis). Parameter estimates are sample moments based on a sample from the posterior distribution of parameters. This sample is generated via iterative sampling from the full conditional distributions of appropriately chosen parameter blocks. Using the device of data augmentation proposed by Tanner and Wong (26), the uncertainty of missing values is incorporated in sampling from the posterior parameter distribution and thus within-parameter estimation via additionally sampling from an approximate full conditional distribution of the missing values. Note that data augmentation facilitates analysis based on full conditional analysis based on complete data structures. Within the Bayesian framework model, comparison is then performed based on the marginal likelihood, allowing comparison of non-nested model specifications. The approach of Chib (27), allowing calculation of the marginal likelihood on the log scale, is adapted to deal with missing data in the explaining variables (see Supplementary Appendix S1 online).

To check the validity of the suggesting modeling, we performed a twofold robustness check. In addition to checking the validity of the assumed first-order trend stationarity against alternative characterizations of the time trending behavior of height increments by means of the marginal likelihood, we compared the model fit for different sets of explaining variables, i.e., we checked the fit of the model with and without the factor $s_{\text {it }}$ and with and without the consideration of tempo controls. Note that approval for conducting this study, in which we reanalyzed anonymized data, was provided by the institutional review board of the University of Bamberg.

\section{SUPPLEMENTARY MATERIAL}

Supplementary material is linked to the online version of the paper at http://www.nature.com/pr

\section{ACKNOWLEDGMENT}

We gratefully acknowledge the generosity of Luciano Molinari, Zurich, Switzerland, from whom we received the data of the First Zurich Longitudinal Growth Study.

\section{STATEMENT OF FINANCIAL SUPPORT}

This study was kindly supported by the German Society for Auxology (Deutsche Gesellschaft für Auxologie).

Disclosure: The authors declared no conflict of interest.

\section{EDITOR'S NOTE}

Pediatric Research recently published another article on the topic of human growth: "The World's Tallest Nation Has Stopped Growing Taller: The Height of Dutch Children From 1955 to 2009," by Schönbeck et al. (Pediatr Res 2013;73:371-7). Aßmann and Hermanussen commented on the Schönbeck et al. article: "The authors show that the young Dutch adults are among the tallest in the world, and since the midnineteenth century have gained some $21 \mathrm{~cm}$ in height. On the other hand, the authors emphasize the amazing lack of any similar trend in the variation of height. It is suggested that the Dutch might have more or less equally benefited from the general improvement in living conditions, but their data lack evidence for a major association between economic factors, life situation, and growth in height. Our conditional-modeling approach might provide an explanation for the marked restriction in the height variation."

\section{REFERENCES}

1. Tanner JM. Growth as a target-seeking function: catch-up and catch-down growth in man. In: Falkner F, ed. Human Growth: A Comprehensive Treatment. New York, London: Plenum Press, 1986:167-79.

2. Fogel RW. The Escape From Hunger and Premature Death, 1700-2100. Cambridge, New York, Melbourne: Cambridge University Press, 2004.

3. Komlos J. Height and social status in eighteenth-century Germany. J Interdisc His 1990;20:607-21.

4. van Wieringen JC. Secular growth changes. In: Falkner F, ed. Human Growth: A Comprehensive Treatment. New York, London: Plenum Press, 1986:307-31.

5. Fredriks AM, van Buuren S, Burgmeijer RJ, et al. Continuing positive secular growth change in The Netherlands 1955-1997. Pediatr Res 2000;47: $316-23$.

6. Staub K, Ruhli FJ, Woitek U, Pfister C. The average height of 18- and 19-year-old conscripts $(n=458,322)$ in Switzerland from 1992 to 2009, and the secular height trend since 1878. Schweiz Med Wochenschr 2011;141:w13238.

7. Pirquet C. Eine einfache Tafel zur Bestimmung von Wachstum und Ernährungszustand bei Kindern (A simple table for determining growth and nutritional status in children). Z Kinderheilkd 1913;O. VI: 253-62.

8. Rosario AS, Schienkiewitz A, Neuhauser H. German height references for children aged 0 to under 18 years compared to WHO and CDC growth charts. Ann Hum Biol 2011;38:121-30.

9. Tanner JM, Whitehouse RH, Marshall WA, Healy MJR, Goldstein H. Assessment of Skeletal Maturity and Prediction of Adult Height (TW2 Method). London, New York, Paris, San Diego, San Francisco, Sidney, Tokyo, and Toronto: Academic Press, 1983.

10. Hermanussen M. Auxology: an update. Horm Res Paediatr 2010;74: $153-64$.

11. Brundtland GH, Liestøl K, Walløe L. Height, weight and menarcheal age of Oslo schoolchildren during the last 60 years. Ann Hum Biol 1980;7: $307-22$.

12. HAGEN W. [On the problem of acceleration]. Dtsch Med Wochenschr 1961;86:220-3.

13. Aswani N, Taylor CJ, McGaw J, Pickering M, Rigby AS. Pubertal growth and development in cystic fibrosis: a retrospective review. Acta Paediatr 2003;92:1029-32.

14. Wiedemann B, Steinkamp G, Sens B, Stern M; German Cystic Fibrosis Quality Assurance Group. The German cystic fibrosis quality assurance project: clinical features in children and adults. Eur Respir J 2001;17: 1187-94.

15. Bogin B, Smith P, Orden AB, Varela Silva MI, Loucky J. Rapid change in height and body proportions of Maya American children. Am J Hum Biol 2002;14:753-61.

16. Muñoz-Hoyos A, Molina-Carballo A, Augustin-Morales M, et al. Psychosocial dwarfism: psychopathological aspects and putative neuroendocrine markers. Psychiatry Res 2011;188:96-101.

17. Ryan ND, Dahl RE, Birmaher B, et al. Stimulatory tests of growth hormone secretion in prepubertal major depression: depressed versus normal children. J Am Acad Child Adolesc Psychiatry 1994;33:824-33.

18. Albertsson-Wikland K, Aronson AS, Gustafsson J, et al. Dose-dependent effect of growth hormone on final height in children with short stature without growth hormone deficiency. J Clin Endocrinol Metab 2008;93:4342-50. 
19. Kumari M, Tabassum F, Clark C, Strachan D, Stansfeld S, Power C. Social differences in insulin-like growth factor-1: findings from a British birth cohort. Ann Epidemiol 2008;18:664-70.

20. Sapolsky RM, Spencer EM. Insulin-like growth factor I is suppressed in socially subordinate male baboons. Am J Physiol 1997;273(4 Pt 2): R1346-51.

21. Prader A, Largo RH, Molinari L, Issler C. Physical growth of Swiss children from birth to 20 years of age. Helv Paediatr Acta 1989;43:1-125.

22. Butler GE, McKie M, Ratcliffe SG. The cyclical nature of prepubertal growth. Ann Hum Biol 1990;17:177-98.
23. Prader A. Catch-up growth. Postgrad Med J 1978;54:Suppl 1:133-46.

24. Hermanussen M, Largo RH, Molinari L. Canalisation in human growth: a widely accepted concept reconsidered. Eur J Pediatr 2001;160: 163-7.

25. Geweke J. Using simulation methods for Bayesian econometric models: inference, development, and communication. Econ Rev 1999;18:1-73.

26. Tanner M, Wong W. The calculation of posterior distributions by data augmentation. J Am Stat Assoc 1987;82:528-40.

27. Chib S. Marginal likelihood from the Gibbs output. J Am Stat Assoc 1995;90:1313-21. 